\title{
Ivan Grujic
}

Nadica Stojanovic

Radivoje Pesic

Aleksandar Davinic

Sunny Narayan

https://doi.org/10.21278/TOF.44105

ISSN 1333-1124

eISSN 1849-1391

\section{NUMERICAL ANALYSIS OF IC ENGINE OPERATION WITH HIGH- PRESSURE HYDROGEN INJECTION}

\begin{abstract}
Summary
The limited quantities of oil reserves and the exhaust emissions from IC engines have become a threat to the existence of IC engines. One of the best solutions to the problem is the use of alternative fuels. Hydrogen is an alternative fuel that is called a fuel of the future. A disadvantage of hydrogen is its high combustion speed. Experimental results were used for the determination of inputs for numerical analysis. The numerical analysis is performed for a 3D model of the engine in order to determine the working parameters of the engine (pressure and temperature). The main goal of this study is to investigate a possibility of modifying the diesel engine so that it can run on hydrogen. It was found that in such an engine the greatest loads occur in the combustion chamber; thus, the vital parts of the engine are protected. Therefore, a mechanical analysis of the combustion chamber was performed (calculation of stresses and deformations). The obtained results are encouraging because they indicate that by applying the presented solution a much cheaper technology than the modern diesel engine systems is made possible.
\end{abstract}

Key words: $\quad$ hydrogen, experimental results, 3D model, numerical analysis, chamber

\section{Introduction}

Internal combustion engines (IC engines) are still indispensable power units for different types of means of transportation. Despite the fact that the first vehicles were powered by electric drives, IC engines have become dominant as power units for different types of vehicles.

Half of the total energy and raw materials on our planet are practically used for the production and exploitation of vehicles [1]. Obviously, the vehicles have very high importance for human lives and the environment, so special attention should be given to them.

From the beginning of the usage of IC engines, two basic types have existed:

- Petrol engines and

- Diesel engines. 
The functional differences between these two types of engines have enabled the use of fuels of various features, but of the same raw material origin - natural oil [2]. So far, the abundance of resources and the economic fuel production have enabled the co-existence of petrol and diesel engines. However, based on the data available from the literature related to the oil trade, it is found that the current oil producers will have been able to meet the demands for oil by the year 2030 [3]. The question is whether this is true or not. Still, it is necessary to keep in mind that such a risk does exist. Accordingly, Fig. 1 shows the forecasts of the natural oil world reserves given as reserves-to-production $(\mathrm{R} / \mathrm{P})$ ratios.

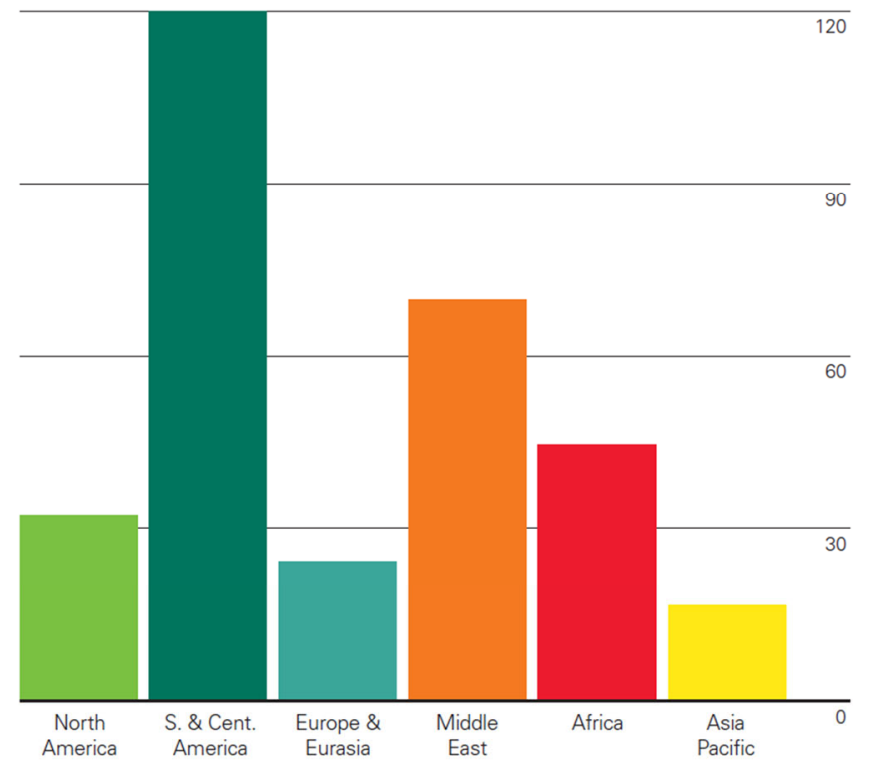

Fig. 1 Forecasts for the world reserves of natural oil [4]

Of course, the limitations on oil resources have caused a constant, but significant increase in oil prices. In addition, combustion of fossil fuels leads to environmental pollution. For these reasons, there is a need for some alternative fuels [5] that can be used instead of oil from the aspect of engine operation and can be cheaper and friendlier to the environment. Among alternative fuels, there are propane, methane, ethanol, and methanol. Hydrogen is a fuel that may be considered as ecologically the cleanest fuel.

Hydrogen is considered to be an unconventional fuel, the same as solar energy [6], and for these reasons, it is considered to be inexhaustible. It represents a favourable substitute for fossil fuels because it has a calorific value of $142 \mathrm{MJ} / \mathrm{kg}$, which is about three times greater calorific value than those of fossil fuels; in addition, hydrogen is available in nature [7]. Taking into account that hydrogen used as a fuel does not contain carbon, it may be considered as a fuel that does not produce substances that cause the greenhouse effect. However, hydrogen used as a fuel for IC engines produces a very large amount of nitrogen oxides; thus, the only advantage is no emission of particulate matters and carbon compounds $\left(\mathrm{CO}\right.$ and $\left.\mathrm{CO}_{2}\right)$.

At first sight, hydrogen has all the qualities of a good fuel [8], but some of its features do not support this claim. Namely, it is generally known that a molecule of hydrogen is the smallest molecule that exists. In the past, hydrogen storage was a real challenge. Today, these difficulties have been overcome for a long time. Another good feature of hydrogen is a wide range of flammability in the air mixture, from $4 \%$ to $75 \%$ of volume. The combustion speed is the worst feature of hydrogen. Due to extremely high combustion speeds, hydrogen is by no means suitable for being used as a fuel. A high combustion speed entails a high degree of pressure increase, which is not good for the lifetime of the engine. The idea of this paper is to 
develop an engine design in which the combustion speed of hydrogen will not pose a serious problem. Before the realisation of such an engine, it is necessary to investigate what other researchers have been doing in this area, what they have been facing, what problems they have encountered and how the problems were solved.

Diesel engines have been considered as one of the biggest polluters for decades. For this reason, researchers intensively work on the ways to reduce the harmful exhaust emission from the diesel engine, in which the most critical substances are particulate matter (PM) and nitrogen oxides $\left(\mathrm{NO}_{\mathrm{x}}\right)$. One of the most common areas of research is a bi-fuel engine [9]. It has been found that by using two fuels, diesel and hydrogen, the emission of harmful combustion products can significantly be reduced. However, the concentration of nitrogen oxides is still extremely high.

In addition to diesel engines, it is also possible to modify petrol engines so that they can run on hydrogen [10]. The classic petrol engine with a multi-point injection (MPI) system has been modified to run on hydrogen. Modifications to the engine were carried out in the intake section, where injectors and a system for preventing the back flame were installed.

One of the ideas for modification is the method of injecting hydrogen directly into the cylinder [10]. However, in this case, the engine does not use hydrogen as the only fuel, but as an additive to petrol. The modification was also made on a conventional petrol engine with an MPI system, with hydrogen injectors placed directly in the engine cylinder. The amount of hydrogen mass added is $10 \%$ of the total mass of the fuel.

By adding $10 \%$ of hydrogen to the fuel, the duration of the combustion process has been reduced to $80 \%$ of the overall duration of the combustion. This is explained by the high combustion speed of hydrogen.

Water is one of the most important resources in the world and in our country. The need for hydrogen is steadily increasing. Today, almost $95 \%$ of hydrogen is obtained from natural gas, $\mathrm{CH}_{4}$. It can also be obtained by the electrolysis of water and the energy required for the process can be provided by the combustion of any fossil fuel or from renewable sources such as hydro energy, wind, and solar energy [11]. In order to do this, it is necessary to find the cheapest and the most efficient way of producing it [12]. Small-scale electrolysis and reformer systems with hydrogen capacities ranging from 50 to 500 normal cubic meters per hour $\left(\mathrm{Nm}^{3} /\right.$ hour) are already commercially available. The specific cost (CAPEX - capital expenditure) of small scale water electrolysers and gas reformers is 5,000-12,000 USD per $\mathrm{Nm}^{3} / \mathrm{hr}$, depending on the capacity of the electrolyser or the reformer $\left(50-500 \mathrm{Nm}^{3} / \mathrm{hr}\right.$ ), or on the technology type (alkaline or PEM - polymer electrolyte membrane) in the case of electrolysers [13].

There are not many studies on this subject. Most likely, the reason for this is that the results of such research are used for practical application, i.e. for possible production of hydrogen-fuelled engines and not for scientific purposes. The aim of this paper is to examine the possibility of modifying diesel engines for operation with hydrogen as the only fuel through; numerical analysis is used for that purpose. If the solution proves to be good, then it may be applied to the real engine for which the numerical analysis was performed. If the results are good, the next step is the experiment. Subsequently, if the experimental results are good, this can lead to a new approach to engine development. The greatest advantages can be an economic benefit and a significant reduction in environmental pollution caused by motor vehicles.

\section{Experimental research}

Before performing the numerical analysis, it is necessary to take into consideration that the engine geometry must be real. This is important because the future research will be 
focused on the experiment that will be performed on a real engine. A single cylinder diesel engine, LDA450, was used as an experimental engine, with characteristics given in Table 1.

Table 1 Test engine specifications

\begin{tabular}{|l|c|}
\hline Engine manufacturer & Lombardini \\
\hline Piston bore [mm] & 85 \\
\hline Piston stroke [mm] & 80 \\
\hline Connecting rod length [mm] & 145 \\
\hline Compression ratio [-] & $17.5: 1$ \\
\hline Engine power [kW] & 7.4 \\
\hline Engine speed [rpm] & 3000 \\
\hline Number of cylinders & 1 \\
\hline Fuel & Diesel fuel \\
\hline Injection angle $\left[{ }^{\circ} \mathrm{CA}\right.$ BTDP] & 18.5 \\
\hline
\end{tabular}

Taking into account that there were no real inputs for the numerical analysis since the experiment with hydrogen as a fuel was not performed, it is necessary to calculate certain inputs. The most important input for the numerical analysis of the engine working cycle is fuel consumption. The experimental diesel engine was previously tested with diesel fuel. Experimental research was carried out for thirteen regimes, according to the European Stationary Cycle (ESC) (Fig. 2). The scheme of the experimental installation is shown in Fig. 3.

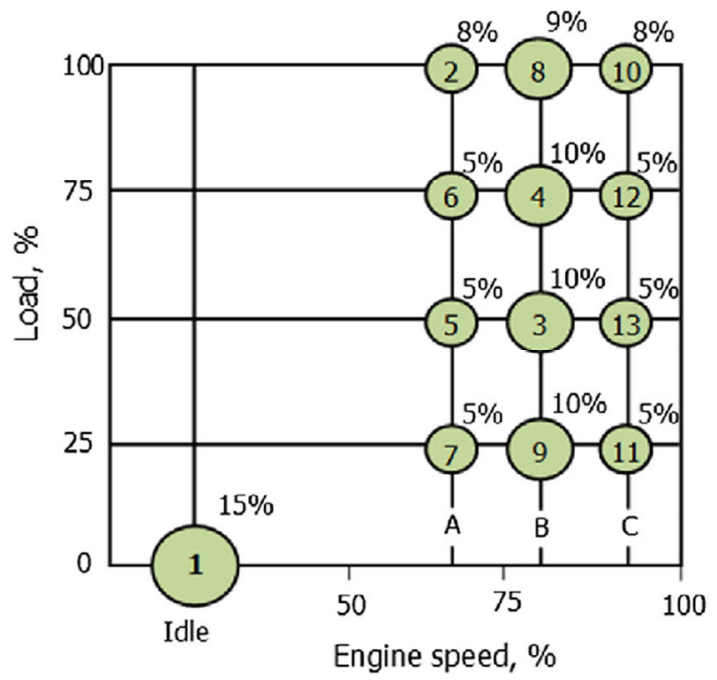

Fig. 2 European Stationary Cycle [14]

Based on the analysis of the ESC, it can be concluded that the regimes 2, 8, and 10 are the most critical ones. Because of the complexity of the analysis itself, only the results obtained in the regime 10 were selected for this analysis. In this regime, there are the maximum engine speed and the maximum load. Because of that, this mode is selected as the best solution. The essential data that are measured are:

- Engine power: $P_{e}=5.842 \mathrm{~kW}$,

- Engine speed: $n=2674 \mathrm{rpm}$,

- Cylinder charge: $\eta_{\mathrm{v}}=0.818$ and

- Air-fuel ratio: $\lambda=1.345$. 


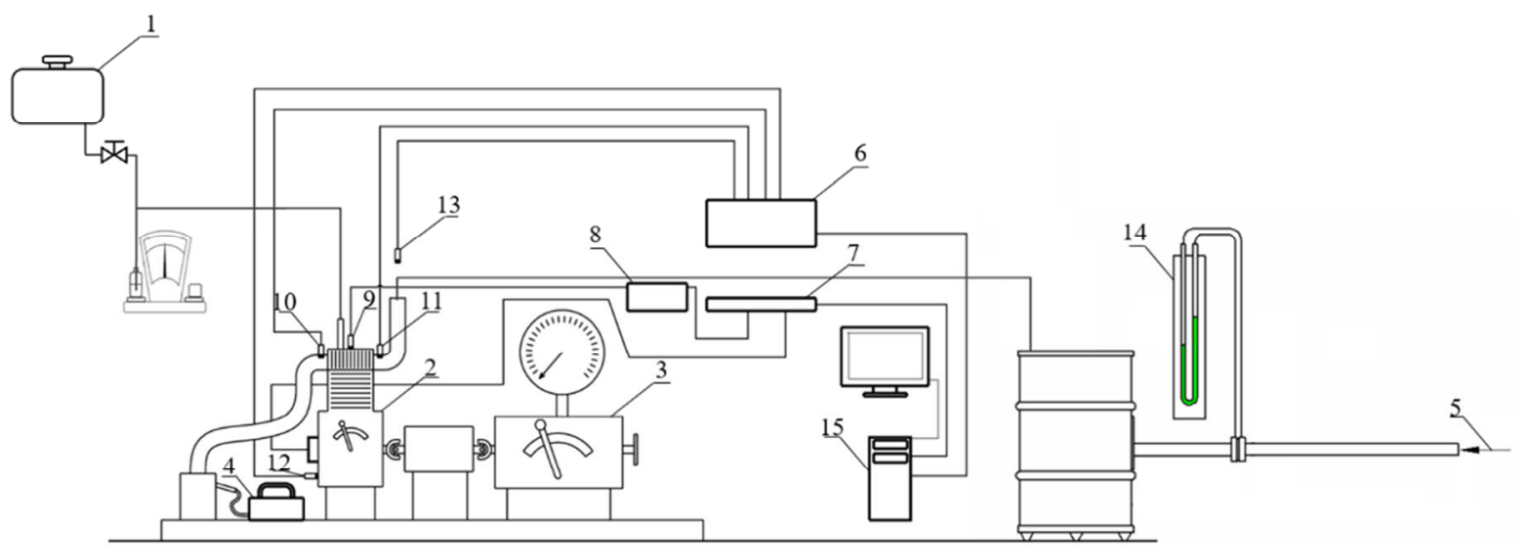

Fig. 3 Measurement installation: 1 - Fuel tank; 2 - Engine; 3 - Dynamometer; 4 - AVL Ditest - the device for engine smoke measurement; 5 - Air flow; 6 - HBM UPM 60 - the device for reading temperatures, measured by temperature sensors; 7 - AVL Indimer 619 - the device for pressure acquisition and measurement

trigger; 8 - Kistler 5007 - amplifier for pressure signal; 9 - Cylinder pressure sensor; 10 - Exhaust port

temperature sensor; 11 - Intake port of temperature sensor; 12 - Oil temperature sensor; 13 - Environment temperature sensor; 14 - U manometer and $15-\mathrm{PC}$

\section{3D model and boundary conditions}

After the experiment, 3D modelling of the engine geometry has been performed; in the model, hydrogen was used as the only fuel. The numerical analysis was performed using the ANSYS software package. A geometry that contains the piston shape, intake and exhaust valves, and inlet and exhaust manifolds is required for the numerical analysis. For this reason, we carried out the modelling of the geometry which corresponds by the shape of the piston and by dimensions to the real experimental engine. In addition, the geometry of the real cylinder contained a combustion chamber which has replaced the diesel fuel injector. The combustion chamber was not an imaginary one; it was already made to fit fully the cylinder head in which it is placed. The 3D model of engine geometry with the combustion chamber can be seen in Fig. 4. The geometry shown in the figure represents the 3D model of the engine cylinder with the piston at the Top Dead Point (TDP).

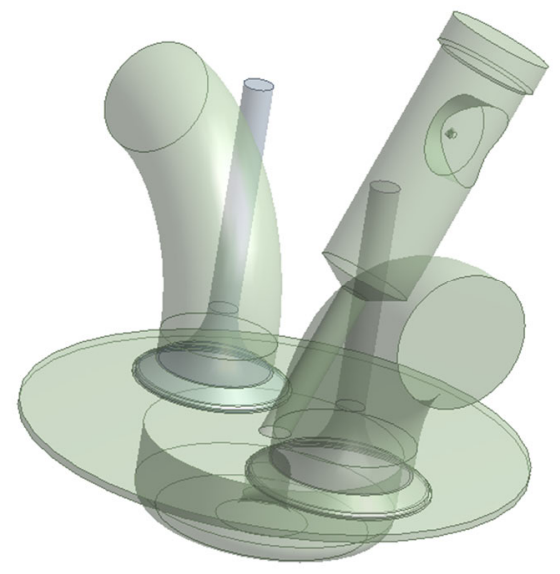

Fig. 4 3D model of engine geometry with a combustion chamber

By adding the combustion chamber to the original version of the engine, the engine volume above the piston is changed. With the change in volume, the compression rate changes and together with the combustion chamber, it is now equal to $13.5: 1$; this means that the combustion chamber occupies $22 \%$ of the total volume of the space above the piston. 
In order to simplify the numerical analysis, it was decided not to simulate the complete cycle of the engine, but only the compression stroke, the combustion process, and the power stroke. By inputting such commands into the program, the need for the intake and exhaust manifolds and for the suction and exhaust valves is eliminated; thus, the engine geometry has the shape shown in Fig. 5.

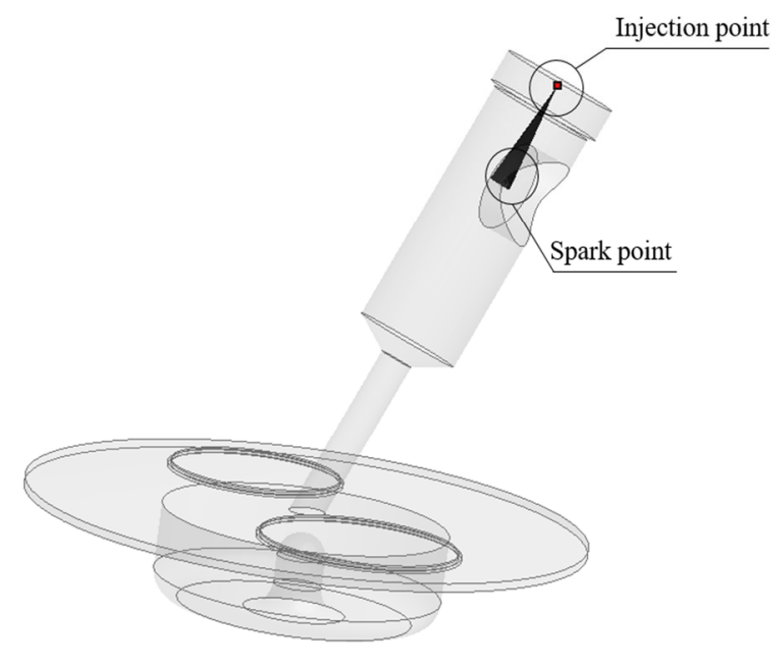

Fig. 5 Engine geometry simplified for the analysis

The geometries from Figs. 4 and 5 represent the interior space of the engine and the combustion chamber. As it can be seen in Fig. 5, the designed geometry contains a place for a spark plug and for an injector. As far as the injector is concerned, only the position of the nozzle (injection point) is visible in this case. It is very important for the designed geometry to correspond to the real one because of the fluid flow during operation. The geometry in Fig. 5 shows the remaining valve heads. The reason for this is the fact that both valves were closed during simulations of the strokes.

The previously measured data were first entered as an input into a thermodynamic calculation with the aim of determining the effective fuel consumption. This is the so-called Grinevecki-Mazing calculation of the engine cycle. The advantage of this calculation is that some of the parameters, such as the chemical composition and the calorific value of the fuel, can be changed. By applying this calculation, it was found that the effective fuel consumption for hydrogen is $118 \mathrm{~g} / \mathrm{kWh}$. By inserting this parameter, as well as the data on the engine speed and the cylinder charge, the boundary conditions for the analysis were defined.

As mentioned before, the compression stroke, the combustion process, and the power stroke were observed. From the engine operating cycle sequence, it is known that the intake valve closes after the Bottom Dead Point (BDP) has been reached and the exhaust valve opens before the BDP is reached. As Fig. 5 shows, both valves are closed during the simulation. For this reason, the moment when the intake valve was closed, which corresponds to 220 degrees, was taken as the beginning of the simulation, and the moment when the exhaust valve was open, which corresponds to 500 degrees, as the end of the simulation. In addition, the initial condition is the pressure in the cylinder defined at the moment the intake valve closes; this piece of data has been taken from the experimental data and it amounts to 0.98 bar, while the temperature at the closing point of the intake valve is calculated using the Grinevecki-Mazing calculation and it amounts to $350 \mathrm{~K}$. The start of the fuel injection was defined at 330 degrees, and the injection duration was 20 degrees. This type of injection corresponds to the high-pressure injection of hydrogen. More accurately, the applied injection pressure is 100 bar. The spark timing is defined at 355 degrees. 


\section{Results and discussion}

The numerical analysis was performed by using the given boundary conditions and the modelled geometry. The basic parameters of the working cycle of the IC engine are pressure and temperature, and only these parameters were considered in the results. Figure 6 shows the cylinder pressure obtained experimentally on a conventional diesel engine for which modifications are planned and also the results obtained by the simulation of an engine working with hydrogen as a fuel.
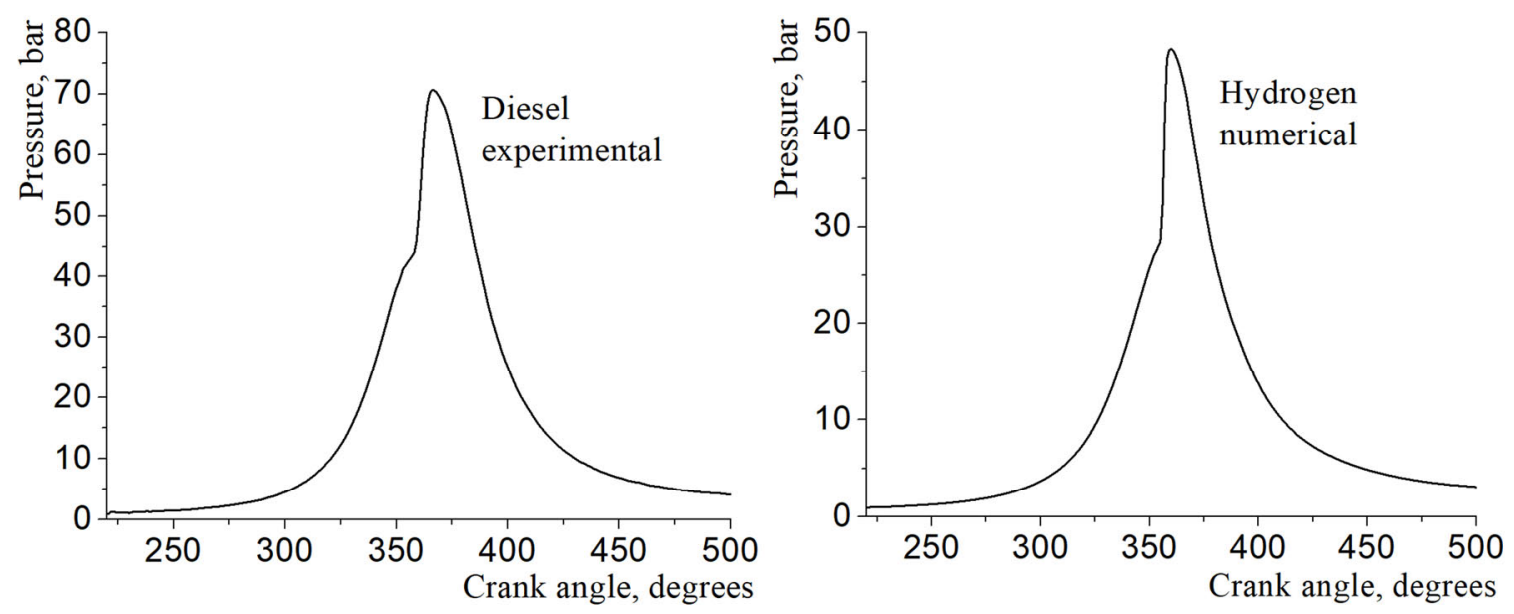

Fig. 6 Cylinder pressure

It can be noted that the maximum pressure in the diesel mode is 71 bar, while the simulation of hydrogen gives a maximum pressure of 48 bar. The difference in the maximum values of pressure can be easily explained. The original compression ratio of experimental engine is 17.5: 1, while that of the altered version with hydrogen would be 13.5: 1 . It is generally known that, when compressing a gas, the compression ratio has a major impact on the maximum value of the pressure at the end of the compression stroke, which, in turn, influences the maximum pressure due to combustion. By reducing the maximum pressure, the mechanical load of the engine decreases, which will favourably affect the life cycle of the engine. However, an important parameter for the lifetime of the engine is the pressure rate increase. In Fig. 6, one can notice that the pressure increase is very sharp from the moment of ignition to the TDP, when the engine runs on hydrogen. This increase in pressure can be easily explained. The pressure ratio increase is very sharp due to the high combustion speed of hydrogen. This confirms the finding from literature [10] about the short duration of the combustion process; a case in which the combustion duration is reduced to $80 \%$ by only $10 \%$ of hydrogen is reported. Despite the logical explanation, the reduced combustion duration can be very bad for the engine construction. The difference in the pressure increase between the hydrogen engine (obtained by the numerical analysis) and the real diesel engine can be noticed in Fig. 7. 
I. Grujic, N. Stojanovic, R. Pesic,

A. Davinic, S. Narayan

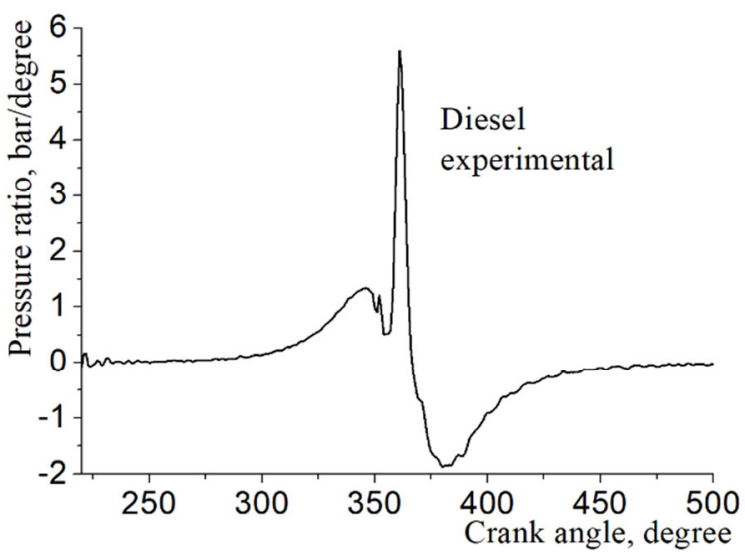

Numerical Analysis of IC Engine Operation with High-Pressure Hydrogen Injection

Fig. 7 Pressure ratio

Figure 7 shows the pressure ratio graph obtained from the experimental data for the conventional diesel engine and that obtained by the numerical analysis of hydrogen-fuelled engine. If the two graphs in Fig. 7 are compared, it can be seen that the maximum value of the pressure ratio of hydrogen combustion was by $33 \%$ higher than that of diesel, despite the difference in the maximum pressure value. This can also be explained by the high speed of hydrogen combustion. This behaviour of the cylinder pressure is not good because of the dynamically varying loads of the engine parts. This is the reason why the combustion chamber may be a very good solution for engines operating on hydrogen. Figure 8 should be observed for a better explanation of this statement.

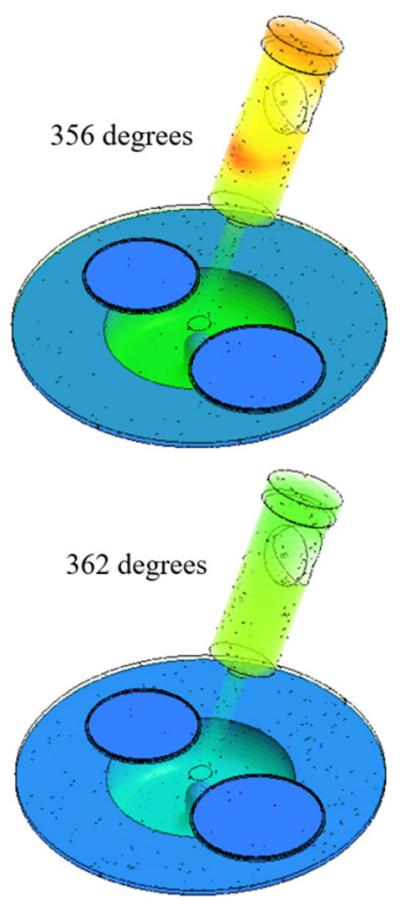

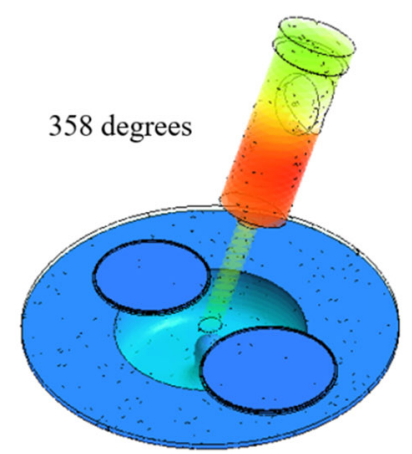

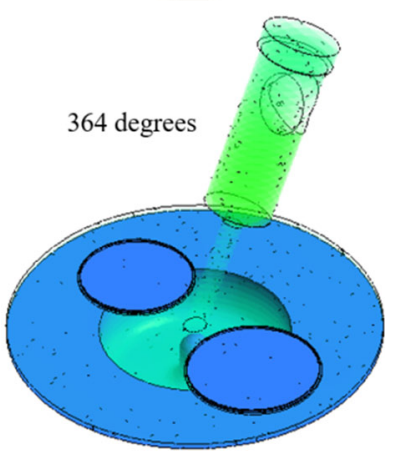

Fig. 8 Pressure contours

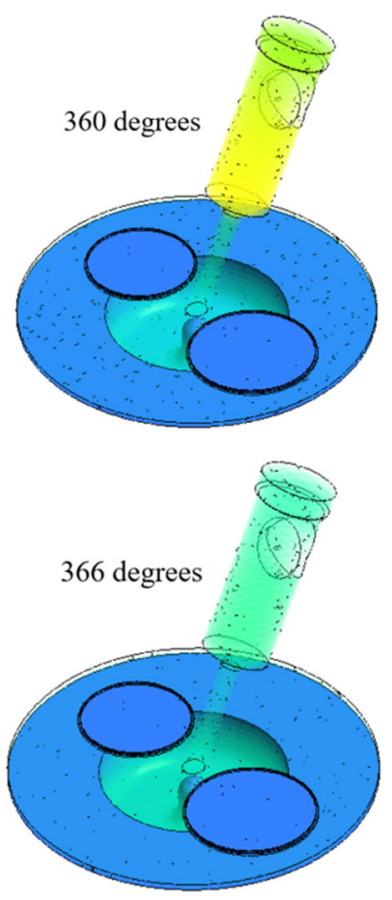

Figure 8 shows the pressure contours that occur in the cylinder and in the combustion chamber. The visualisation of the processes in the engine is one of the advantages of numerical analysis. The initial angle is 356 degrees, which corresponds to the angle of the ignition of the hydrogen-air mixture in the chamber. It can be concluded that the pressure in the combustion chamber is higher than the pressure in the cylinder for angle values up to 366 degrees; this value was selected as the end of the display. Thus, it can be concluded that the 
fastest pressure wave that causes very dynamic pressure changes appears first in the combustion chamber, while the equilibrium between the pressures in the combustion chamber and the cylinder occurs later. The obtained results are encouraging because the combustion chamber suffers the greatest loads, while the rest of the engine is protected due to the muffling properties of the combustion chamber geometry.

The temperature that occurs during the engine operation is an important parameter of the engine working cycle that should be considered. Figure 9 shows the temperature obtained experimentally from the diesel engine and the temperature obtained by the numerical analysis of hydrogen engine.

When comparing the diagrams in Fig. 9, one can notice that there is a sharper temperature rise in the hydrogen engine than in the diesel engine, while the maximum temperature is higher in the diesel engine. In addition, after the phase of uncontrolled combustion, which is reflected in a sudden increase in temperature, there are some very interesting results for both the experimental diesel engine and the simulated hydrogen engine. Of course, in the diesel engine, there is a slight decrease in temperature, which, in fact, represents the phase of controlled combustion and the after-burning phase. Unlike the case of diesel engine, in the case of hydrogen engine a sudden drop in temperature can be expected based on simulation results. This type of combustion resembles the operation of petrol engines; this is logical because the combustion of the mixture of hydrogen and air is included just after the injection of the total amount of fuel, while in diesel engines, the combustion and fuel injection are simultaneous.
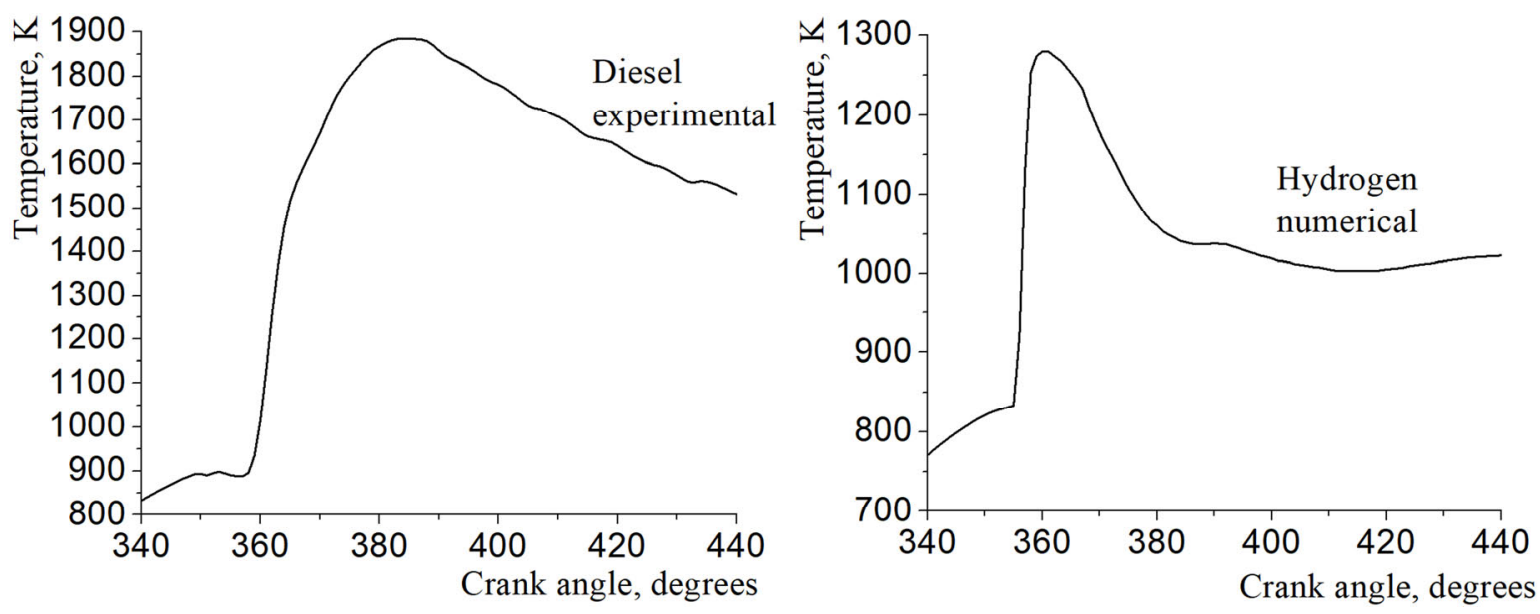

Fig. 9 Temperatures during the combustion process

In the conditions of the stoichiometric mixture, the hydrogen combustion temperature is around $2100 \mathrm{~K}$. But in this case, the lean mixture is used. The use of different mixtures can be the subject of future research. In addition, the temperature that is obtained by the numerical analysis is the temperature that occurs in the cylinder, or more precisely, the heat loss because of the chamber.

It has been stated that, with the use of the combustion chamber and its muffling effect, the engine main parts are less loaded because the highest loads occur in the chamber. However, a question arises: what happens with the combustion chamber? In order to determine stresses and deformations that occur in the combustion chamber, a mechanical analysis of the combustion chamber was carried out. The boundary conditions are the numerically obtained pressure from Fig. 6 and the numerically obtained temperature from Fig. 9. The results of the mechanical analysis of the combustion chamber are given in Fig. 10. 
The combustion chamber shown in Fig. 10 differs in appearance from the combustion chamber in Fig. 8. The reason is that Fig. 10 shows the exterior appearance of the combustion chamber, while Fig. 8 shows the interior, which is important for the flow of the gasses during the working cycle. Naturally, the obtained values of pressure and temperature are set to act on the interior of the combustion chamber.

Stresses and deformations obtained by the numerical analysis of previously calculated values of pressure and temperature are shown in Fig. 10. It can be noted that the highest stress value is $212.45 \mathrm{MPa}$; this value is much lower than the Young modulus of the stainless steel, the material that was selected as the material for the combustion chamber. Based on the results, it can be concluded that the combustion chamber will withstand the specified operating conditions and that its mechanical properties will not be deteriorated. In addition, Fig. 10 shows the deformations of the combustion chamber, where the highest deformation value is $0.098 \mathrm{~mm}$. This value of deformation is extremely small, which is a good thing. The highest deformation values occur on the insert that serves the purpose of fastening the spark plug. It should be noted that in the case of mechanical analysis, no cooling of the combustion chamber was set, which is normal for the real engine. Therefore, it is quite possible to expect lower values of stress and deformation in future research that will most likely be experimental. Pressure and temperature were obtained according to the data that simulate the operation of the engine in the most loaded regime, which means that these values would be lower in the mild modes of engine operation.

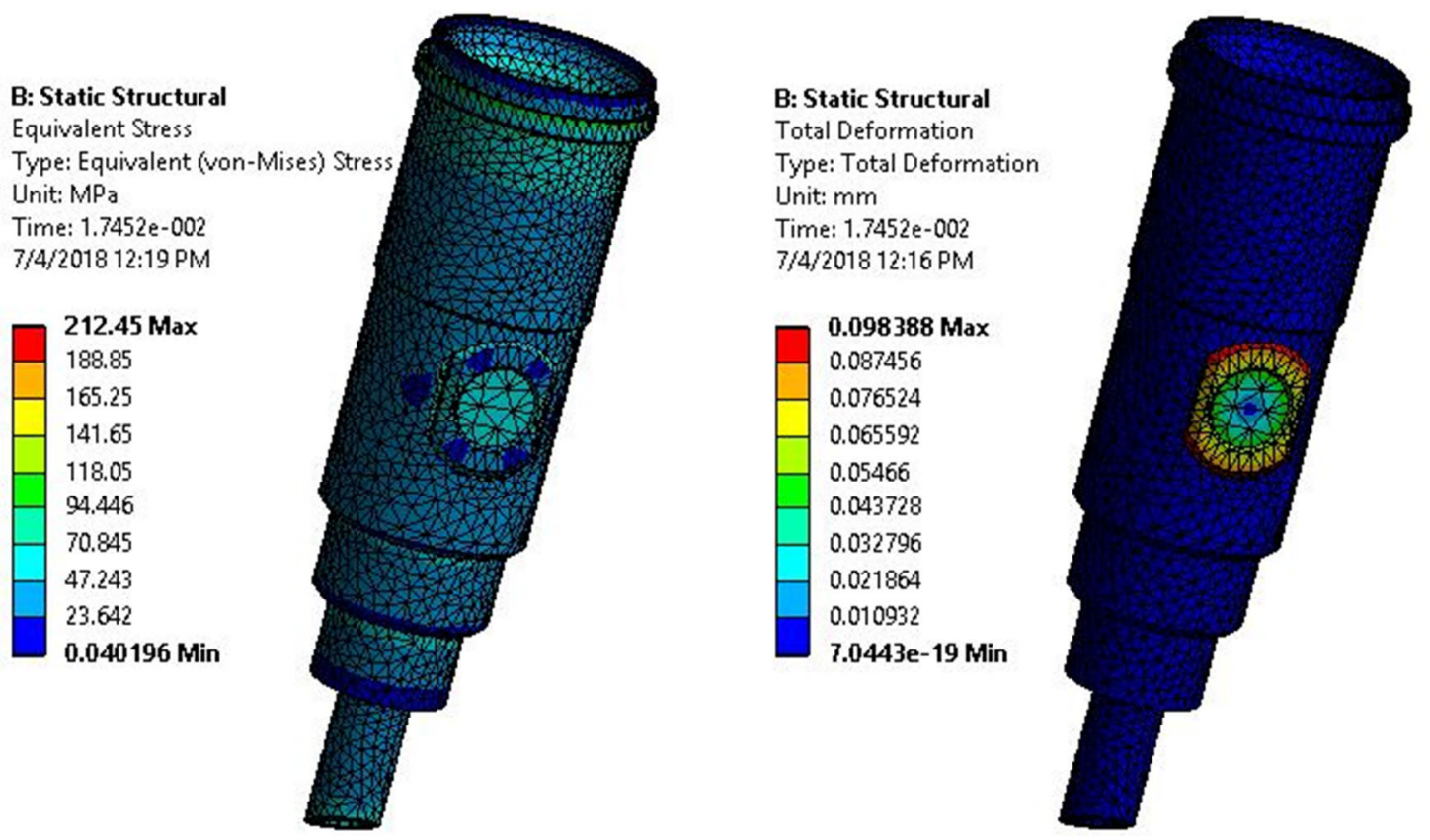

Fig. 10 Combustion chamber stresses and deformations

\section{Conclusions}

Hydrogen is commonly referred to as an alternative fuel of the future. The generally known fact is that hydrogen is all around us. In this paper, one of the ideas how to convert classic diesel engine to run on hydrogen is presented. The combustion chamber is not a new technological solution for the diesel engine. However, it can be a new technological solution if it is applied as explained in the paper.

Analysing the results obtained, it can be said that the research goal is achieved. Regarding the obtained values of pressures and temperatures, it can be clearly stated that such 
an engine will work normally. Also, a high pressure ratio will not affect the engine parts because of the fact that the combustion chamber gives protection to other parts of the engine. A numerical analysis has shown that the combustion chamber will withstand the stresses that occur during engine operation. Of course, there are huge heat losses in the combustion chamber, but if there is an inexhaustible and cheap fuel such as hydrogen at disposal, this disadvantage is not a problem. It may even be possible to use this heat for something else, like for a heating system. In addition, this kind of modification entails a cheap technology compared to the technology used in contemporary diesel engines.

The combustion chamber designed and presented in the paper has already been manufactured and the preparations for its use are in progress. It has a seat fitted with an injector used for the injection of petrol in direct injection engines and a spark plug. In order for this system to operate, the only requirement is to assemble electronics for controlling the injector and the spark plug; this is a far less expensive option than the today's equipment for common rail systems used in diesel engines. In addition, the combustion chamber allows different injection systems to be adopted in order to optimise the combustion process.

In future research, the entire cycle will be simulated. In this way, engine power, torque, and forces that occur in the piston mechanism can be calculated.

\section{ACKNOWLEDGMENTS}

This paper was realised within the research project "The research of vehicle safety as part of a cybernetic system: Driver-Vehicle-Environment" ref. no. TR35041, funded by the Ministry of Education, Science and Technological Development of the Republic of Serbia.

\section{REFERENCES}

[1] Pešić B.R., Davinić Lj.A., Taranović M.D., Miloradović M.D., Petković D.S. Experimental determination of double Vibe function parameters in diesel engines with biodiesel. Thermal Science 2010, 14, 207-218. https://doi.org/10.2298/tsci100505069p

[2] Davinić Lj.A. Identification of the characteristics of the multiprocessing operation of the piston IC engine, PhD thesis. University of Kragujevac, Faculty of Engineering, 2013.

[3] Kjarstad .J, Johnsson F. Resources and future supply foil. Energy Policy 2009, 37, 441-464. https://doi.org/10.1016/j.enpol.2008.09.056

[4] BP Global. BP Statistical Review of World Energy June 2017, https://www.bp.com/content/dam/bpcountry/de_ch/PDF/bp-statistical-review-of-world-energy-2017-full-report.pdf [Accessed 30 September 2018]. https://doi.org/10.1177/014459878900700615

[5] Pourkhesalian M.A., Shamekhi H.A., Salimi F. Alternative fuel and gasoline in an SI engine: A comparative study of performance and emissions characteristics. Fuel 2010, 89, 1056-1063. https://doi.org/10.1016/j.fuel.2009.11.025

[6] Jain P.I. Hydrogen the fuel for 21st century. International Journal of Hydrogen Energy 2009, 34, 73687378. https://doi.org/10.1016/j.ijhydene.2009.05.093

[7] Grochala W., Edwards P.P. Thermal decomposition of the non-interstitial hydrides for the storage and production of hydrogen. Chemical Reviews 2004, 104, 1283-1316. https://doi.org/10.1021/cr030691s

[8] Verhelst S, Wallner T. Hydrogen-fueled internal combustion engines. Progress in Energy and Combustion Science 2009;35:490-527. https://doi.org/10.1016/j.pecs.2009.08.001

[9] Dimitriou P., Tsujimura T. A review of hydrogen as a compression ignition engine fuel. International Journal of Hydrogen Energy 2017, 42, 24470-24486. https://doi.org/10.1016/j.ijhydene.2017.07.232.

[10] Sopena C., Dieguez P.M., Sainz D., Urroz J.C., Guelbenzu E., Gandia L.M. Conversion of a commercial spark ignition engine to run on hydrogen: Performance comparison using hydrogen and gasoline. International Journal of Hydrogen Energy 2010, 35, 1420-1429. https://doi.org/10.1016/j.ijhydene.2009.11.090

[11] Kurko S. Influence of boron induced modification in $\mathrm{MgH}_{2}$ structure on dehydrogenation process, $\mathrm{PhD}$ thesis. University of Belgrade, Faculty of Physical Chemistry, 2015. 
I. Grujic, N. Stojanovic, R. Pesic,

A. Davinic, S. Narayan
Numerical Analysis of IC Engine Operation with High-Pressure Hydrogen Injection

[12] Solmaz R. Electrochemical preparation and characterization of C/NieNiIr composite electrodes as novel cathode materials for alkaline water electrolysis. International Journal of Hydrogen Energy 2013, 38, 2251-2256. https://doi.org/10.1016/j.ijhydene.2012.11.101

[13] IEA Hydrogen. Global trends and outlook for hydrogen, http://ieahydrogen.org/pdfs/Global-Outlook-andTrends-for-Hydrogen_Dec2017_WEB.aspx [Accessed 29 October 2018]

[14] Nabi M.N., Zare A., Hossain F.M., Rahman M.M., Bodisco T.A., Ristovski Z.D., Brown R.J. Influence of fuel-borne oxygen on European Stationary Cycle: Diesel engine performance and emissions with a special emphasis on particulate and NO emissions. Energy Conversion and Management 2016, 127, 187 198. https://doi.org/10.1016/j.enconman.2016.09.010

Submitted: $\quad 07.01 .2019$

Accepted: $\quad 28.10 .2019$
Ivan Grujic

Nadica Stojanovic

Radivoje Pesic

Aleksandar Davinic

University of Kragujevac,

Faculty of Engineering,

34000 Kragujevac, Serbia

Sunny Narayan

Department of Mechanical Engineering,

College of Engineering, Qassim

University, 51452 Buraydah, Saudi Arabia 